\title{
ERG-associated protein with SET domain (ESET)-Oct4 interaction regulates pluripotency and represses the trophectoderm lineage Leng-Siew Yeap ${ }^{1}$, Katsuhiko Hayashi1,2 and M Azim Surani*1
}

\author{
Address: ${ }^{1}$ Wellcome Trust/Cancer Research UK Gurdon Institute, University of Cambridge, Cambridge, UK and ${ }^{2}$ Department of Anatomy and Cell \\ Biology, Graduate School of Medicine, Kyoto University, Yoshida-Konoe-Cho, Sako-Ku, Kyoto 606-8501, Japan \\ Email: Leng-Siew Yeap - lsy20@cam.ac.uk; Katsuhiko Hayashi - khayashi@anat2.med.kyoto-u.ac.jp; M \\ Azim Surani* - a.surani@gurdon.cam.ac.uk \\ * Corresponding author
}

This article is available from: http://www.epigeneticsandchromatin.com/content/2/1/12

(C) 2009 Yeap et al; licensee BioMed Central Ltd.

This is an Open Access article distributed under the terms of the Creative Commons Attribution License (http://creativecommons.org/licenses/by/2.0), which permits unrestricted use, distribution, and reproduction in any medium, provided the original work is properly cited.

\begin{abstract}
Background: Pluripotency, the capacity for indefinite self-renewal and differentiation into diverse cell types is a unique state exhibited by embryonic stem (ES) cells. Transcriptional regulators, such as Oct4, are critical for pluripotency, but the role of epigenetic modifiers remains to be fully elucidated.

Results: Here, we show that ERG-associated protein with SET domain (ESET), a histone methyltransferase enzyme, maintains pluripotency through repression of $\mathrm{Cdx2}$, a key trophectoderm determinant, by histone $\mathrm{H} 3$ lysine 9 trimethylation $(\mathrm{H} 3 \mathrm{~K} 9 \mathrm{me} 3)$ of the promoter region. Notably, this repression is mediated through the synergistic function of small ubiquitinrelated modifier (SUMO)ylated ESET and Oct4. ESET localises to the promyelocytic leukaemia (PML) nuclear bodies and is SUMOylated in ES cells. Interaction of ESET with Oct4 depends on a SUMO-interacting motif (SIM) in Oct4, which is critical for the repression of $C d x 2$.

Conclusion: Loss of ESET or Oct4 results in strikingly similar phenotypes both in ES cells with their differentiation into trophectoderm cells, and in early embryos where there is a failure of development of the pluripotent inner cell mass (ICM) of blastocysts. We propose that SUMOylated ESET-Oct4 complex is critical for both the initiation and maintenance of pluripotency through repression of differentiation, particularly of the trophectoderm lineage by epigenetic silencing of Cdx2.
\end{abstract}

\section{Background}

ERG-associated protein with SET domain (ESET), also known as SET domain bifurcated 1 (SETDB1), is a histone methyltransferase that catalyses a repressive mark on euchromatin by mediating histone 3 lysine 9 trimethylation (H3K9me3) [1,2]. The ESET protein contains a Tudor domain, a methyl-CpG binding domain and a bifurcated SET domain that is responsible for its catalytic activity [3]. Proteins that associate with ESET are mainly corepressors
[1,4-7], in agreement with its repressive role. ESET is critical for very early development since the Eset-null embryos die at the peri-implantation stage with defective development of the inner cell mass (ICM), from which no embryonic stem (ES) cells could be derived [8]. The Eset-null phenotype is similar to that of Oct4-null embryos [9] but the basis for this is unknown. We decided to address this question by investigating the role of ESET in the ICMderived pluripotent ES cells. 


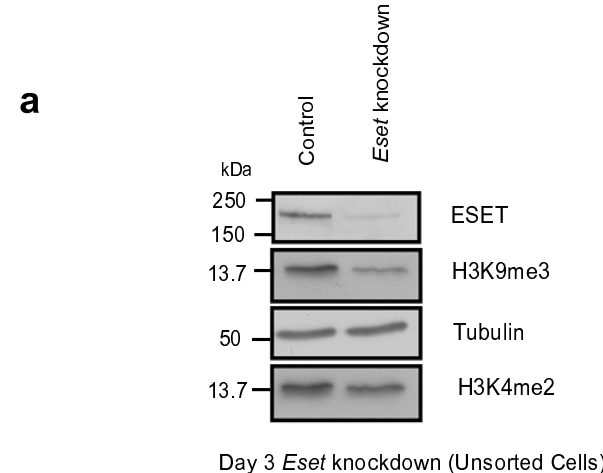

b
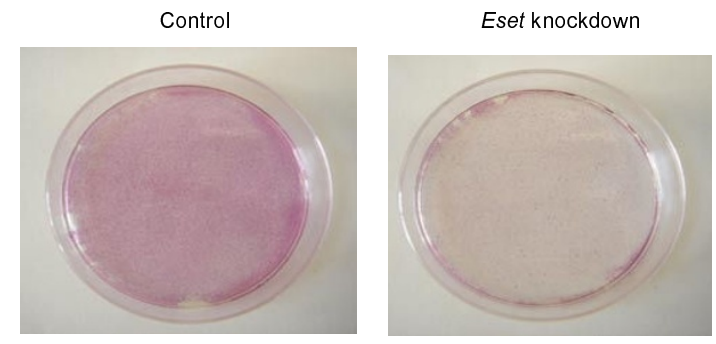

Day 7 Eset knockdown (Unsorted Cells)

C

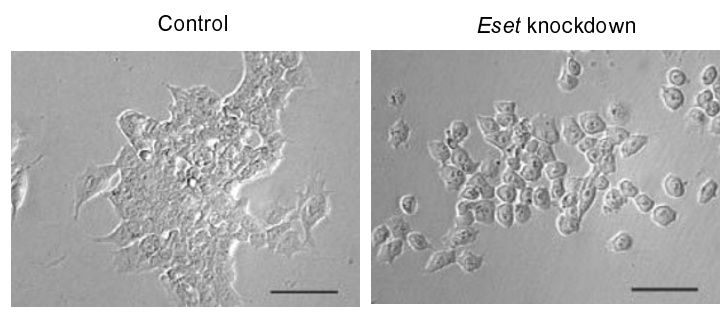

Day 5 Eset knockdown (Sorted Cells) d

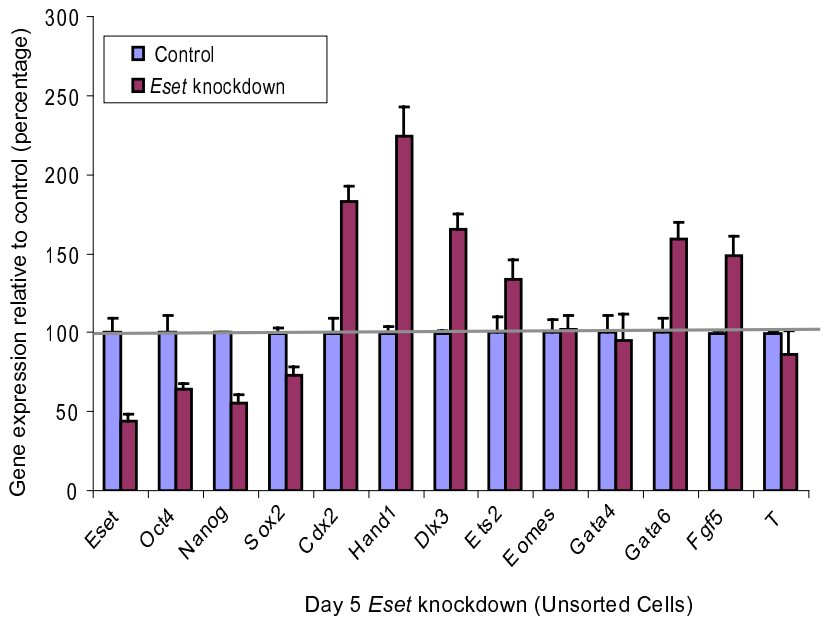

e

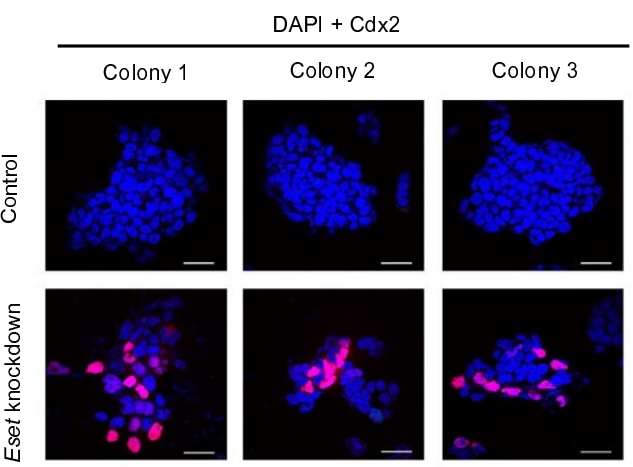

Day 7 Eset knockdown (Sorted Cells)

\section{Figure I}

ERG-associated protein with SET domain (ESET)-depleted embryonic stem (ES) cells differentiate towards the trophectoderm lineage. (a) Western blot shows downregulation of ESET and histone 3 lysine 9 trimethylation (H3K9me3) in Eset knockdown ES cells at day 3 of short hairpin RNA (shRNA) transfection. Tubulin and H3K4me2 served as loading control. (b) Alkaline phosphatase staining of Eset knockdown (right panel) and control (left panel) ES cells after 7 days of shRNA transfection. (c) Morphology of fluorescence-activated cell sorting (FACS)-sorted Eset knockdown (right panel) and control (left panel) ES cells at day 5 of shRNA transfection. Scale bar, $50 \mu \mathrm{m}$. (d) Gene expression levels in Eset knockdown ES cells relative to control cells after normalising against Gapdh, a house keeping gene. Error bars, standard deviation (SD) of three technical replicates. (e) Images of three representative colonies from three different wells of control (top panel) and Eset knockdown (bottom) ES cells which were purified by FACS at day 3 of shRNA transfection followed by 4 days of culture in medium that is conducive for development of trophectoderm cells (TS medium). Cdx2-positive cells are labelled in red. Nuclei are labelled in blue. Scale bar, $100 \mu \mathrm{m}$. 


\section{Results and Discussion ESET-depleted ES cells differentiate towards the trophectoderm lineage}

To investigate the role of ESET in ES cells, we induced knockdown of Eset using a short hairpin RNA (shRNA)expressing vector that contains an enhanced green fluorescent protein (EGFP) reporter (Figure 1a). An empty vector was used as a control. At 7 days following transfection of Eset shRNA, we observed a dramatic loss of pluripotent ES cells as judged by a marked reduction in the number of alkaline phosphatase positive cells (Figure 1b, Additional file 1). To visualise the morphology of the knockdown cells, EGFP-positive cells were purified by fluorescent activated cell sorting (FACS), $24 \mathrm{~h}$ after transfection and cultured in ES medium for 2 to 4 days (Figure 1c, Additional file 1). Notably, ES cells transfected with Eset shRNA appeared flat and differentiated, which was clearly distinct from control ES cells, which formed compact colonies (Figure 1c). This experiment demonstrates that ESET is important for the maintenance of undifferentiated ES phenotype.

Next, 5 days after transfection of Eset shRNA, we carried out reverse transcription quantitative polymerase chain reaction (Q-PCR) analysis to determine the precise consequences of Eset knockdown. Concomitant with the change in the phenotype in ESET-depleted ES cells, we found downregulation of pluripotency-specific genes, including Oct4, Nanog and Sox2. At the same time, we detected upregulation of genes associated with differentiation, including, Cdx2, Hand1, Dlx3, Ets2, Fgf5 and Gata6 (Figure 1d). Notably, this response is similar to that triggered by the knockdown of Oct4 in ES cells, where genes associated with the trophectoderm lineage, such as $C d x 2$ and the primitive endoderm lineage, such as Gata6 are upregulated [10]. Thus, apart from the failure of ICM development and pluripotent cells in early embryos following the loss of either Eset [8] or Oct4 [9], the response of ES cells to the loss of these two genes is also comparable.

The upregulation of trophectoderm-specific genes is of particular interest as mouse ES cells have a low propensity to differentiate into trophectoderm cells [11]. This is, at least in part, because Oct4 and Cdx2 induce reciprocal inhibition to achieve a mutually exclusive expression in the pluripotent and the trophectoderm lineages, respectively [12]. Since Eset knockdown evidently exhibits a similar outcome as Oct4 knockdown in ES cells, we investigated whether ESET, like Oct4, might also play a role in repressing trophectoderm differentiation. We tested this possibility by investigating whether ESETdepleted ES cells could give rise to trophectoderm cells. To do this, we cultured ESET-depleted ES cells in a medium that is conducive for development of trophectoderm cells (henceforth called TS medium) [13]. Notably, Cdx2-positive cells were observed in about $40 \%$ of Eset knockdown cells after 4 days of culture in TS medium (Figure 1e). By contrast, the majority of EGFP-negative cells cultured in the TS medium, which represents a concurrent control, were negative for $\mathrm{Cdx} 2$, except for a few cells that are occasionally positive (less than $1 \%$ of total cells), which arise spontaneously when ES cells are exposed to TS medium. The heterogeneity of expression of Cdx2 in ESET-depleted ES cells suggests that, apart from the trophectoderm cells, these ESET-depleted cells may differentiate into other lineages. Nevertheless, ESET-depleted ES cells clearly have a propensity to differentiate towards the trophectoderm lineage, a response that is uncharacteristic of normally differentiating ES cells. To gain mechanistic insight on the role of Eset in regulating pluripotency of ES cells, we decided to focus our analysis on $C d x 2$, since this is an early and a key determinant of the trophectoderm lineage [14].

\section{ESET-mediated H3K9me3 represses Cdx2 in ES cells}

Since the loss of Eset from ES cells results in the upregulation of $C d x 2$ at the mRNA and protein levels, we reasoned that $C d x 2$ might be repressed by ESET-mediated epigenetic modification at its promoter region via H3K9me3. To test for this possibility, we first performed chromatin immunoprecipitation (ChIP) for H3K9me3 at the Cdx2 promoter region in wild-type ES cells. We detected H3K9me3 marks that were spread throughout the $5 \mathrm{~kb}$ region surrounding the transcription start site of $C d x 2$ gene (Figure 2a, b, Additional file 2). In contrast, H3K9me3 levels were not enriched at the promoter region of Oct4 gene, which unlike $C d x 2$ is transcriptionally active in ES cells (Figure 2a, b).

To investigate whether ESET is the histone methyltransferase responsible for $\mathrm{H} 3 \mathrm{~K} 9 \mathrm{me} 3$ modification at the $\mathrm{Cd} 2 \mathrm{x}$ promoter region, we performed ChIP analysis on ES cells. H3K9me3 was detected at the $C d x 2$ promoter region, but this signal was downregulated in ESET-depleted cells by an average of $40 \%$ to $50 \%$ compared to control cells (Figure 2c, Additional file 2). This observation was confirmed by Q-PCR analysis using primers C1 and C2 (Figure 2d). As an additional control, we also analysed the H3K9me3 at the major satellite region that is known to be mediated by Suv39h1/2, a histone methyltransferase that governs $\mathrm{H} 3 \mathrm{~K} 9 \mathrm{me} 3$ at the pericentric heterochromatin region $[15,16]$. In contrast to the observations on the $C d x 2$ promoter region, $\mathrm{H} 3 \mathrm{~K} 9 \mathrm{me} 3$ levels at the major satellite region were unaffected in ESET-depleted ES cells (Figure $2 \mathrm{c}$, Additional file 2). These results suggest that the H3K9me3 marks at the $C d x 2$ promoter region were most likely mediated by ESET.

To further confirm that ESET mediates H3K9me3 at the $C d x 2$ promoter region in ES cells, we performed ChIP 
a

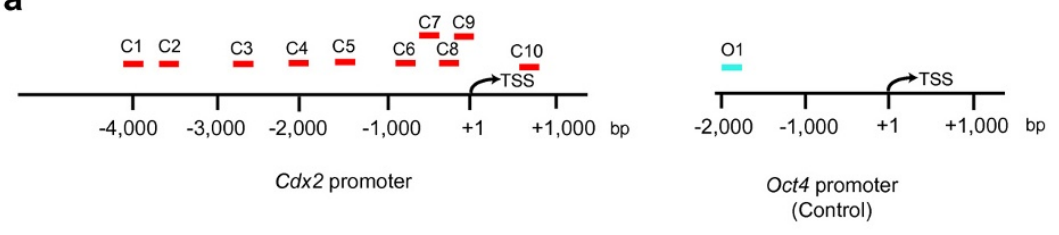

b

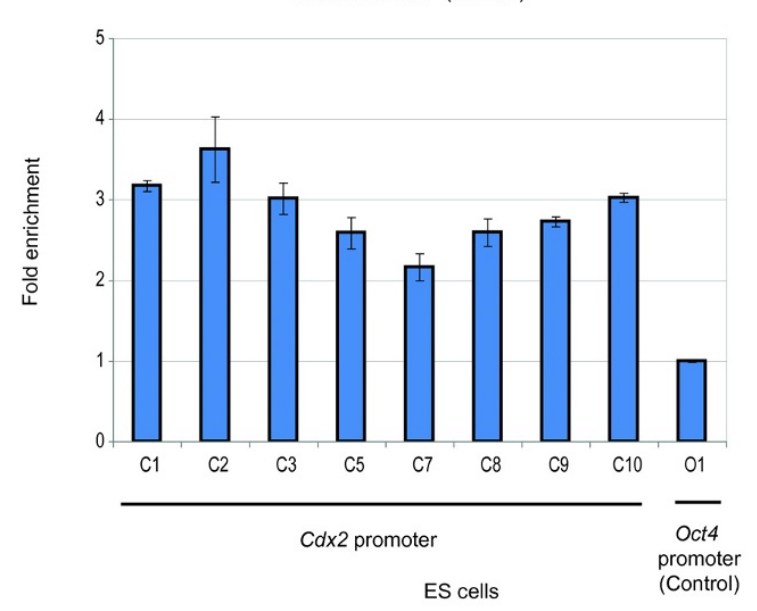

c

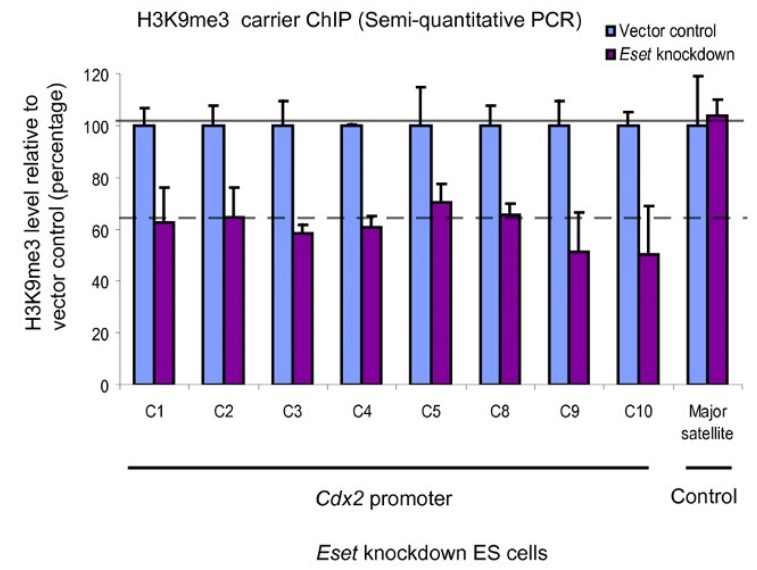

d $\quad \mathrm{H} 3 \mathrm{~K} 9 \mathrm{me} 3$ carrier ChIP (Q-PCR)

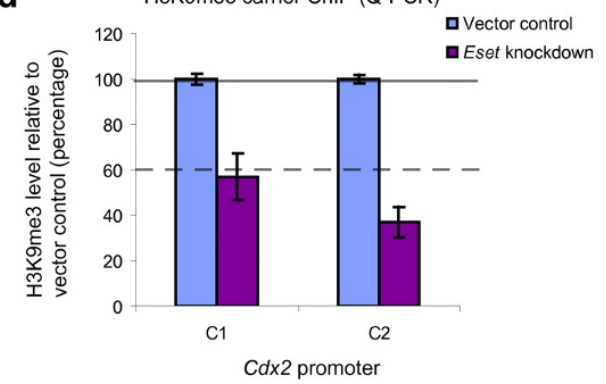

Eset knockdown ES cells

e

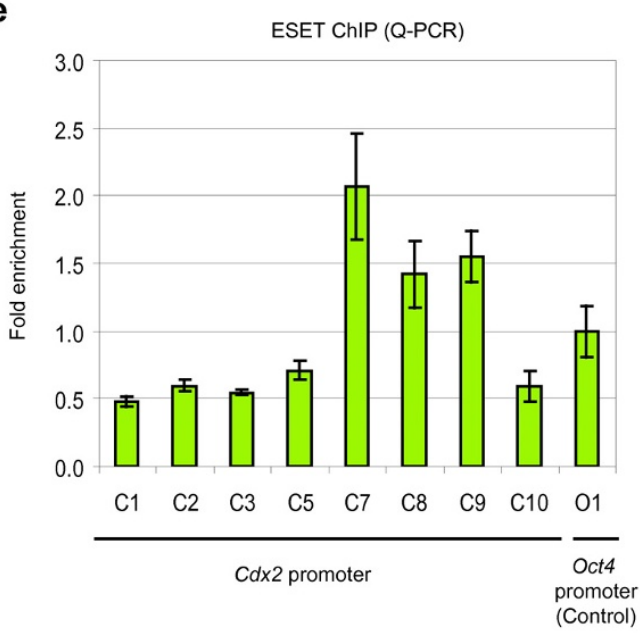

ES cells

Figure 2 (see legend on next page) 
Figure 2 (see previous page)

ERG-associated protein with SET domain (ESET)-mediated histone 3 lysine 9 trimethylation (H3K9me3) represses $\boldsymbol{C d x} 2$ in embryonic stem (ES) cells. (a) Chromatin immunoprecipitation (ChIP) primers $\mathrm{Cl}$ to $\mathrm{ClO}$ used to detect enrichment of $\mathrm{H} 3 \mathrm{~K} 9 \mathrm{me} 3$ on $\mathrm{Cd} \times 2$ promoter (left). Primers $\mathrm{Ol}$ of Oct4 promoter served as a negative control (right). The numbers below the bars indicate distance from transcription start site (TSS) in base pairs (bp). (b) Quantitative polymerase chain reaction (Q-PCR) analysis of the enrichment of $\mathrm{H} 3 \mathrm{~K} 9 \mathrm{me} 3$ at different positions along $\mathrm{Cdx} 2$ promoter region relative to the Oct4 promoter region after normalising against H3 ChIP and IgG controls. Primers C4 and C6 were not suitable for QPCR analysis. Error bars, standard deviation (SD) of three technical replicates. (c) Carrier ChIP semiquantitative PCR analysis of $\mathrm{H} 3 \mathrm{~K} 9 \mathrm{me} 3$ at the $\mathrm{Cd} 2 \mathrm{2}$ promoter and major satellite regions of fluorescence-activated cell sorting (FACS)-sorted Eset knockdown ES cells relative to control cells after normalising against their respective input and lgG controls. Primers C6 and C7 were not suitable for carrier ChIP analysis. Error bars, SD of three independent experiments. (d) Q-PCR analysis of the levels of $\mathrm{H} 3 \mathrm{~K} 9 \mathrm{me} 3$ at region $\mathrm{Cl}$ and $\mathrm{C2}$ of the $\mathrm{Cdx} 2$ promoter in Eset knockdown ES cells relative to control cells after normalising against their respective input and IgG controls. Error bars, SD of three independent experiments. (e) Q-PCR analysis of the enrichment of ESET on different positions along the $C d x 2$ promoter relative to the Oct4 promoter after normalising against their respective input and IgG controls. Error bars, SD of three technical replicates.

using an anti-ESET antibody. We detected enrichment of ESET on $C d x 2$ promoter with a peak at the region immediately upstream of the transcription start site, which was amplified by primer C7 (Figure 2e). Collectively, these results demonstrate that ESET-mediated H3K9me3 represses $C d x 2$ in ES cells.

\section{Oct4 and ESET synergistically repress Cdx2}

Next, we considered whether Oct4 and ESET act synergistically to repress $C d x 2$ since loss of function of Eset and Oct4 generate similar phenotypes, both during early embryonic development [8,9], and in ES cells, as described above. First, we confirmed that Oct4 is enriched on $C d x 2$ promoter in wild-type ES cells (Figure $3 a$ ) as reported previously [17]. Notably, Oct4 is enriched at the same region that is bound by ESET (Figure 2e), suggesting that both factors might coregulate $C d x 2$. To address this possibility, we used ZHBTc4 ES cells that contain a tetracycline regulatable Oct4 allele [18]. Depletion of Oct4 from these ES cells following addition of tetracycline to the culture medium results in the induction of Cdx2 after 2 days (Figure 3b). To analyse the effect of Oct4 depletion on the binding of ESET to $C d x 2$ promoter, we performed ChIP analysis on ZHBTc4 ES cells at day 1 of tetracycline treatment when ESET expression was not yet affected by the depletion of Oct4 (Figure 3b). As expected, Oct 4 binding on the $C d x 2$ promoter was downregulated by $90 \%$ in Oct4-depleted ES cells (Figure 3c). Notably, this was accompanied by downregulation of ESET binding on the $C d x 2$ promoter by $30 \%$ (Figure $3 c$ ). Furthermore, downregulation of ESET binding was coupled with the decline of H3K9me3 levels at the $C d x 2$ promoter region (Figure $3 d)$. We further verified that the binding of ESET to $C d x 2$ promoter is dependent on Oct4 by performing ChIP experiments in ZHBTc4 ES cells overexpressing haemagglutinin (HA)-tagged ESET (Additional file 3). In this experiment, tetracycline was first added to ZHBTc4 cells to initiate loss of Oct4, followed 1 day later by transfection of HA-tagged ESET, followed by a ChIP experiment 1 day further on using an anti-HA antibody. The results show that ESET binding to $C d x 2$ promoter decreased by $40 \%$ confirming that the loss of Oct 4 affects the binding of ESET to $C d x 2$ promoter. Taken together, these results suggest that ESET and Oct4 likely cooperate to repress $C d x 2$, which is consistent with the observation that depletion of either ESET or Oct4 leads to upregulation of Cdx2.

Since $C d x 2$ is a known target of Oct $4[12,17,19]$, it is possible that Oct 4 may interact with ESET to repress $C d x 2$. To test for this possibility, we coexpressed Oct 4 and ESET in $293 \mathrm{~T}$ cells and found that ESET coimmunoprecipitated with Oct4 (Additional file 3). To further investigate which domain of ESET interacts with Oct4, we generated two deletion constructs; HA-ESET- $\Delta$ SET and HA-ESET- $\Delta$ Tudor (Additional file 3 ). Interestingly, when we coexpressed

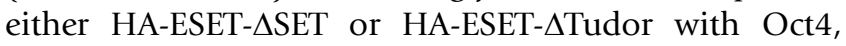
both mutants were able to coimmunoprecipitate with Oct4 (Additional file 3), suggesting that ESET and Oct4 form a complex through bridging proteins, or that ESET associates with Oct4 through at least two different sites. We also performed immunoprecipitation of endogenous ESET in ES cells using an anti-ESET antibody and found that Oct4 was coimmunoprecipitated independently of DNA, albeit at a low level and only when immunoprecipitation was carried out under mild conditions (Figure $3 e$ and Additional file 4). However, in the reciprocal immunoprecipitation experiment using an anti-Oct4 antibody, we noticed that immunoprecipitation of endogenous Oct4 not only precipitated the expected ESET protein of $180 \mathrm{kDa}$, but also ESET proteins of higher molecular weight, which may be post-translationally modified ESET proteins (Figure $4 \mathrm{e}$, lane 7 , top panel and Additional file 4 ). We therefore sought to investigate these modified ESET proteins. 
a

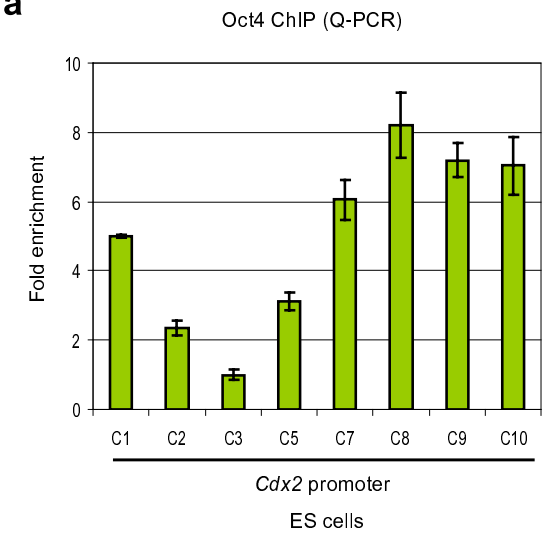

d

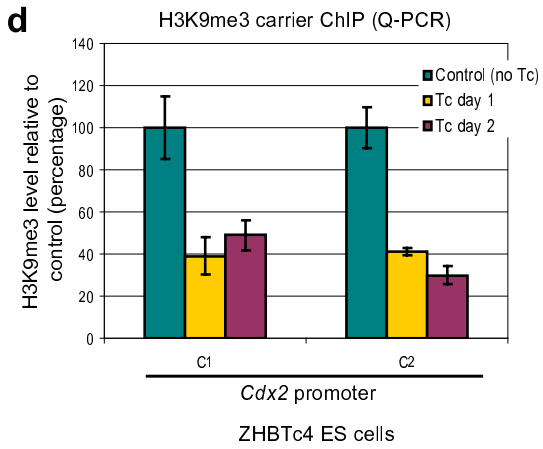

b

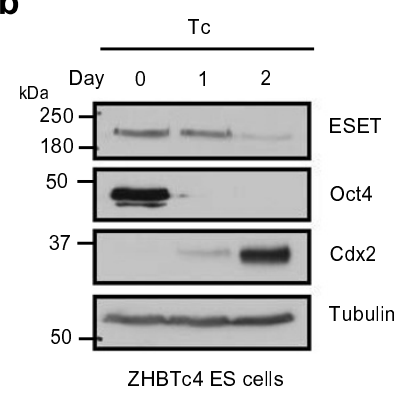

C

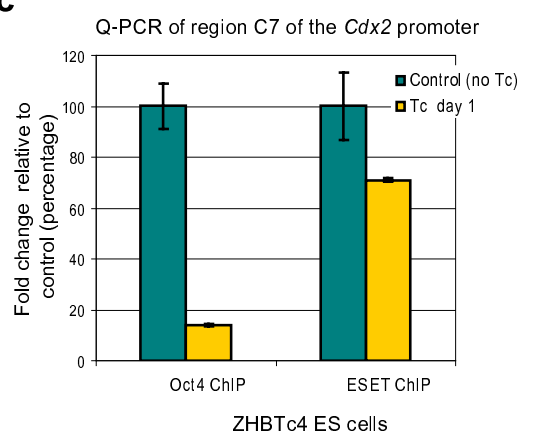

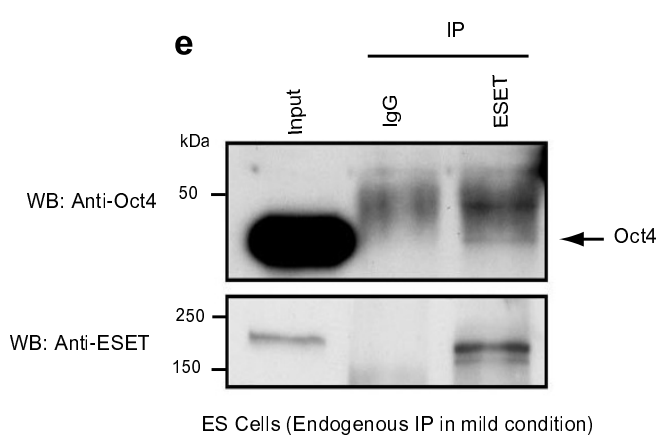

Figure 3

Oct4 and ERG-associated protein with SET domain (ESET) synergistically repress Cdx2. (a) Quantitative polymerase chain reaction (Q-PCR) analysis of the enrichment of Oct4 on different positions along the Cdx2 promoter relative to the least enriched region (C3) after normalising against their respective input and IgG controls. Error bars, standard deviation (SD) of three technical replicates. (b) Western blot shows upregulation of Cdx2 and downregulation of ESET upon depletion of Oct4 at day 2 of tetracycline (Tc) treatment of ZHBTc4 embryonic stem (ES) cells. (c) Q-PCR analysis of the levels of Oct4 and ESET enrichment at region C7 of the $C d x 2$ promoter in ZHBTc4 ES cells treated with Tc for I day relative to untreated cells after normalising against their respective input. Error bars, SD of three independent experiments. (d) Carrier chromatin immunoprecipitation (ChIP) Q-PCR analysis of the levels of histone 3 lysine 9 trimethylation $(\mathrm{H} 3 \mathrm{~K} 9 \mathrm{me} 3)$ at region $\mathrm{Cl}$ and $\mathrm{C2}$ of the $\mathrm{Cdx2}$ promoter in ZHBTc4 ES cells treated with Tc for the indicated days relative to untreated cells after normalising against their respective input and IgG controls. Error bars, SD of three independent experiments. (e) ES cell lysates were immunoprecipitated (IP) with anti-ESET antibody (kind gift of HH Ng; see text) under mild conditions in digitonincontaining buffer and subjected to western blotting (WB) with the antibodies indicated. Rabbit lgG was used as a negative control.

ESET localises to promyelocytic leukaemia (PML) nuclear bodies and is post-translationally modified by small ubiquitin-related modifier (SUMO)

We had noted that ESET has a very striking pattern of subcellular localisation in ES cells, where it is mainly found in punctate foci specifically within the euchromatin region as indicated by the absence of 4',6-diamidino-2phenylindole (DAPI) staining (Figure 4a). Notably, we found that these ESET punctate foci overlap with PML nuclear bodies (Figure 4b). Coimmunoprecipitation experiments in 293T (Additional file 5) and ES cells under mild conditions (Figure $4 \mathrm{c}$ and Additional file 4) show that ESET interacts with PML. PML nuclear bodies are of interest because these are highly organised structural and functional domains that are composed of the PML protein and various other proteins that are involved in different biological functions $[20,21]$. Post-translational modification of PML through addition of SUMOs is pivotal for the formation of PML nuclear bodies [22,23], and many proteins found in the PML nuclear bodies are SUMOylated $[24,25]$. Since ESET colocalises to PML nuclear bodies and interacts with PML in ES cells, we investigated whether ESET undergoes SUMOylation. 

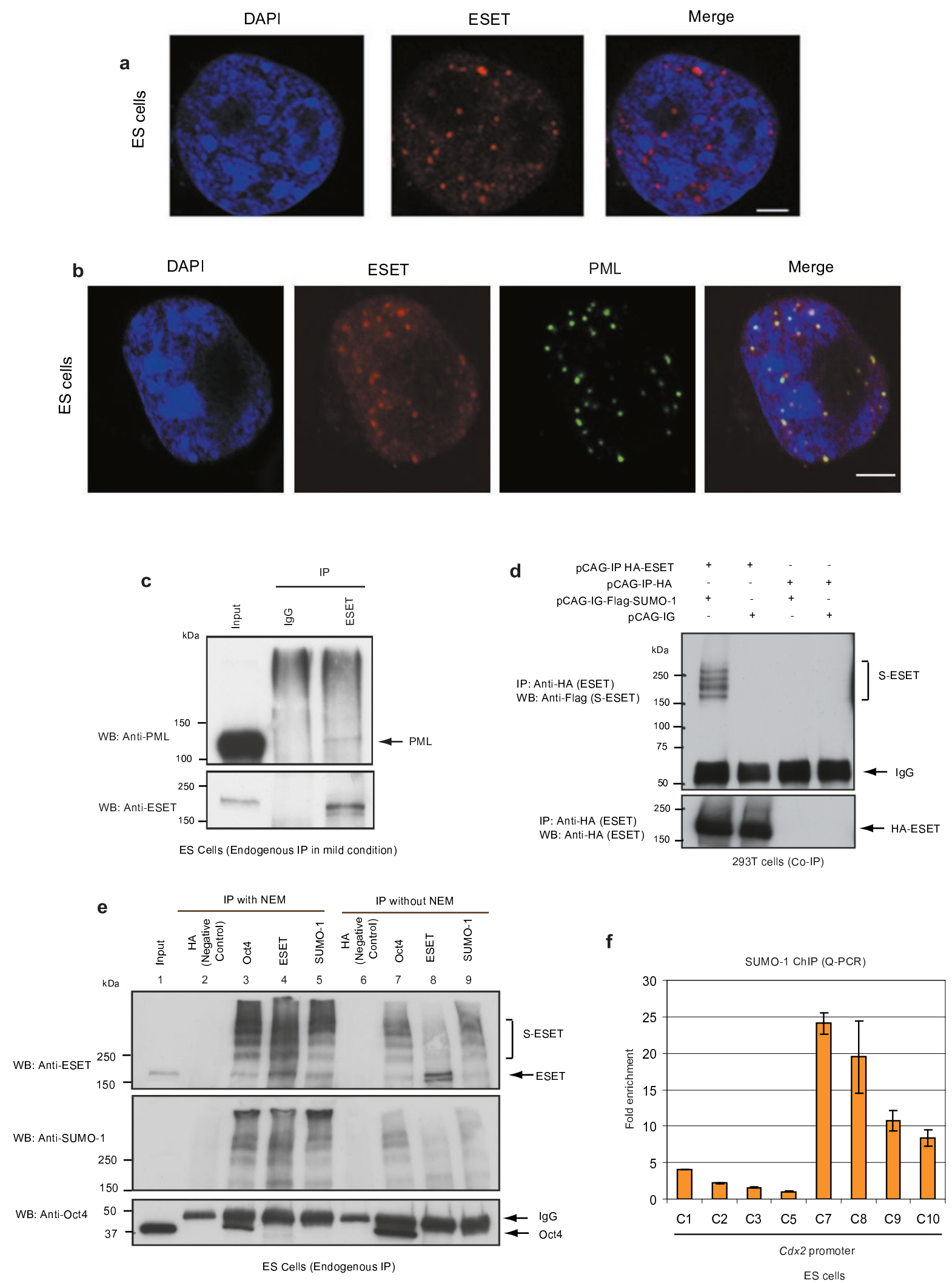

Figure 4 (see legend on next page) 
Figure 4 (see previous page)

ERG-associated protein with SET domain (ESET) localises to promyelocytic leukaemia (PML) nuclear bodies and is post-translationally modified by small ubiquitin-related modifier (SUMO). (a) ESET (red) localises to distinct, punctate foci in euchromatin regions, as indicated by the absence of DAPI (blue) staining in embryonic stem (ES) cells. Scale bar, $3 \mu \mathrm{m}$. (b) ESET (red) localises to distinct, punctate foci that overlaps with PML nuclear bodies (green) in ES cells. Nuclei are labelled in blue. Scale bar, $5 \mu \mathrm{m}$. (c) ES cell lysates were immunoprecipitated (IP) with anti-ESET antibody (kind gift of $\mathrm{HH} \mathrm{Ng}$; see text) under mild conditions in digitonin-containing buffer and subjected to western blotting (WB) with the antibodies indicated. Rabbit IgG was used as a negative control. (d) Western blot analysis of coimmunoprecipitation experiment in 293T cells transfected with haemagglutinin (HA)-ESET and/or Flag-SUMO-I. S-ESET represents SUMOylated ESET. (e) ES cell lysates were immunoprecipitated (IP) with the indicated antibodies in NP40-containing buffer either in the presence or absence of $\mathrm{N}$-ethylmaleimide (NEM) and subjected to western blotting (WB) using $4 \%$ to I5\% Tris- $\mathrm{HCl}$ gradient gel. A rabbit anti-HA antibody was used as negative control. (f) Quantitative polymerase chain reaction (Q-PCR) analysis of the enrichment of SUMO-I on different positions along $C d x 2$ promoter relative to the least enriched region (C5) after normalising against their respective input and IgG controls. Error bars, standard deviation (SD) of three technical replicates.

To test this hypothesis, HA-ESET and Flag-SUMO-1 were cotransfected in $293 \mathrm{~T}$ cells and cell lysates were subjected to immunoprecipitation in the presence of $N$-ethylmaleimide (NEM), an inhibitor of SUMO isopeptidases. When cell lysate was immunoprecipitated with anti-HA antibody (to immunoprecipitate ESET) and immunoblotted with anti-Flag antibody (to visualise SUMOylated ESET), we observed several slower migrating ESET proteins, which may be indicative of different degrees of SUMOylation of ESET protein (Figure 4d). This result suggests that ESET may be SUMOylated in ES cells and that the high molecular weight ESET proteins that interact with Oct4 are probably SUMOylated forms of ESET proteins.

To confirm that the various larger forms of ESET proteins being immunoprecipitated by Oct4 are SUMOylated ESET, we performed immunoprecipitation of ESET from ES cell lysate in the presence of NEM. We found that ESET was indeed SUMOylated as shown by immunoblotting with anti-ESET and anti-SUMO-1 antibodies (Figure $4 e_{\text {, }}$ lane 4). Similarly, the immunoprecipitant from antiSUMO-1 antibody (Figure 4e, lane 5) produced the same, high molecular weight bands as observed with the immunoprecipitant from either anti-ESET (Figure $4 \mathrm{e}$, lane 4 ) or anti-Oct4 (Figure 4e, lane 3) antibodies. More importantly, these bands were less prominent when immunoprecipitation was carried out without the addition of NEM (Figure $4 \mathrm{e}$, lanes 6 to 9). In addition, the higher molecular weight ESET proteins corresponding to SUMOylated ESET were also observed with the immunoprecipitant from anti-PML antibody (Additional files 4 and 5). Collectively, these data confirmed that the higher molecular weight ESET proteins that interact with Oct4 are SUMOylated ESET suggesting that SUMOylated ESETOct4 interaction is required for the repression of $C d x 2$.

Consistent with this, we show by ChIP experiments that SUMO-1 is highly enriched on $C d x 2$ promoter (Figure $4 \mathrm{f}$ ), most notably at the region that was amplified by primer
C7, which happens to be the region where ESET was also most enriched (Figure 2e). The presence of SUMO-1 and ESET at the same region on $C d x 2$ promoter suggests that SUMOylated ESET binds to $C d x 2$, although we cannot rule out a possibility that other SUMOylated proteins might be present in the same region.

\section{Delocalisation of ESET from PML nuclear bodies enhances the interaction of SUMOylated ESET and Oct4}

We then considered whether the localisation of ESET to the PML bodies is crucial for its interaction with Oct4. To do this, we performed shRNA knockdown of Pml in ES cells. Notably, we found that ESET punctate foci were lost in PML-depleted ES cell nuclei (Figure 5a, white border), although the ESET protein levels remained unaltered (Figure 5c: compare lanes 1 and 2). Furthermore, confocal images suggested that the ESET protein was now uniformly dispersed throughout the ES nuclei. Notably, this delocalisation of ESET from PML nuclear bodies increased its interaction with Oct4 (Figure 5b, lane 4). In the reciprocal immunoprecipitation experiments, more SUMOylated ESET was found to associate with Oct4 (Figure $5 c$, lanes 4 and 6). This observation suggests that the scaffold composed of PML regulates the interaction between SUMOylated ESET and Oct4, perhaps by modulating the levels of SUMOylated ESET. These results are consistent with our observations that Oct4 preferentially interacts with SUMOylated ESET.

\section{SUMO-interacting motif (SIM) of Oct4 is crucial for the interaction with ESET and the repression of Cdx2}

To further confirm the interaction of Oct4 and SUMOylated ESET, we attempted to map the sumoylation sites of ESET and the SIM in Oct4. The consensus sumoylation site sequence is $\neg$-Lys-X-Glu/Asp ( $\neg \mathrm{KxE} / \mathrm{D})$, where $\neg$ is a large hydrophobic amino acid and X is any amino acid [26]. Based on the sumoylation prediction software, SUMOplot (Abgent, San Diego, California, USA), many putative sumoylation sites were found in the 
a

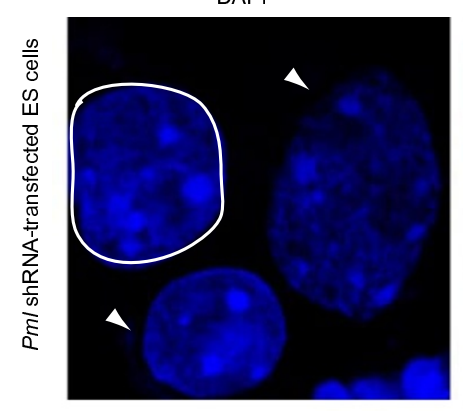

ESET

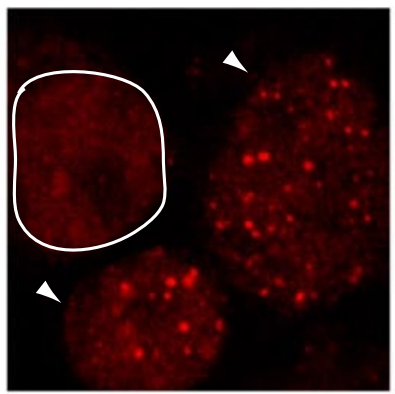

PML

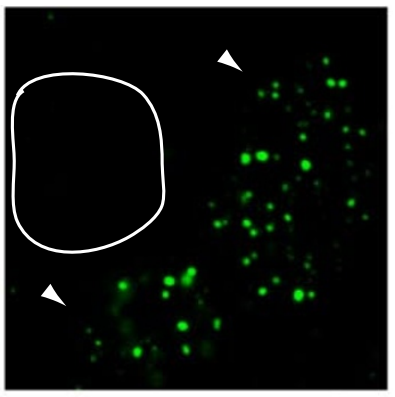

Merge

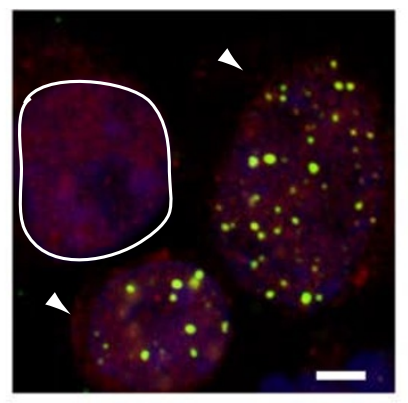

b
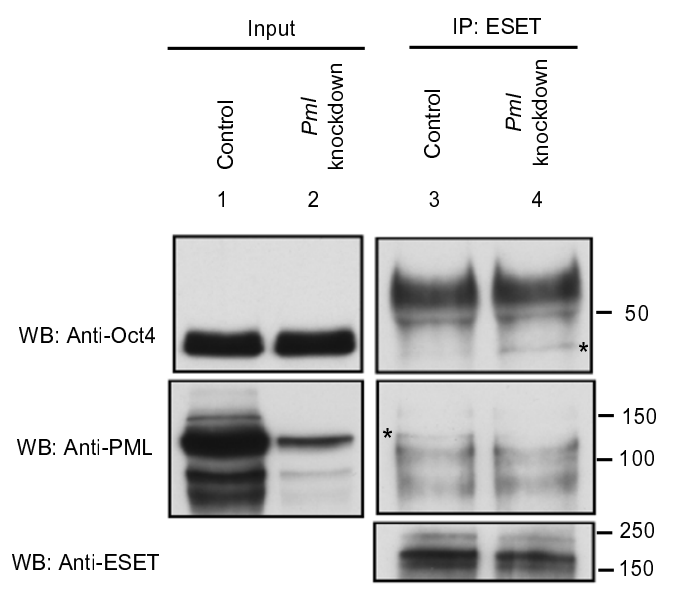

Pml knockdown ES cells (Endogenous IP with EtBr)
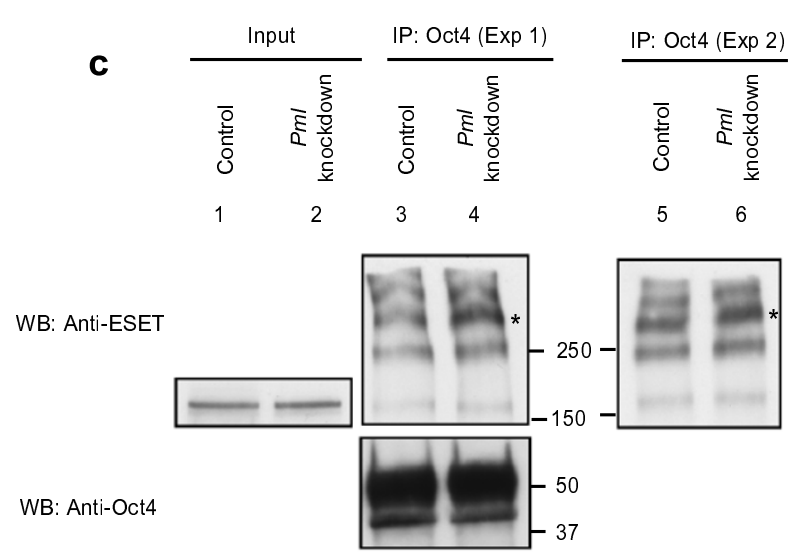

$P m l$ knockdown ES cells (Endogenous IP in mild condition with EtBr)

Figure 5 (see legend on next page) 
Figure 5 (see previous page)

Delocalisation of ERG-associated protein with SET domain (ESET) from promyelocytic leukaemia (PML) nuclear bodies promotes the interaction of small ubiquitin-related modifier (SUMO)ylated ESET and Oct4. (a) In PML (green)-depleted embryonic stem (ES) cells (white border), ESET (red) punctate foci were delocalised from PML nuclear bodies. Nuclei are labelled in blue. Scale bar, $3 \mu \mathrm{m}$. Cultures also contain cells which were not depleted of PML, where ESET exhibit punctate foci (arrow heads) associated with PML bodies. (b) ES cells transfected with Pml short hairpin RNA (shRNA) for 4 days were immunoprecipitated (IP) with anti-ESET antibody (kind gift of HH Ng; see text) under mild conditions in buffer containing digitonin and ethidium bromide, and were subjected to western blotting (WB) with the antibodies indicated. Note that more Oct4 is precipitated by ESET in Pml knockdown ES cells (*lane 4, top panel). Asterisk (lane 3, middle panel) indicates PML being precipitated by ESET in control cells transfected with an empty vector but not in Pml knockdown ES cells (compare with lane 4, middle panel). (c) ES cells transfected with Pml shRNA for 4 days were immunoprecipitated (IP) with anti-Oct4 antibody in buffer containing NP40, N-ethylmaleimide, and ethidium bromide and subjected to WB using $4 \%$ to I 5\% Tris- $\mathrm{HCl}$ gradient gel. More SUMOylated ESET was precipitated by Oct4 in two independent experiments (Exp I and Exp 2 ) in Pml knockdown cells as indicated (*; lane 4 and 6, top panel).

ESET protein (Additional file 6). This is consistent with our observation that SUMOylated ESET exhibited multiple bands when immunoprecipitated with Oct4. Furthermore, this would also explain why both the Tudor domain-containing and SET domain-containing fragments of ESET were found to interact with Oct4 (Additional file 3). Nevertheless, the presence of a large number of putative sumoylation sites in ESET complicates their functional analysis through mutation of these sites. However, only one putative SIM was found in Oct4 (Figure $6 a)$. We thus focussed our studies on investigating the Oct4 SIM.

Proteins that contain the SIM with the consensus Val/Ile$\mathrm{X}-\mathrm{Val} / \mathrm{Ile}-\mathrm{Val} / \mathrm{Ile}(\mathrm{V} / \mathrm{I}-\mathrm{X}-\mathrm{V} / \mathrm{I}-\mathrm{V} / \mathrm{I})$ in which $\mathrm{X}$ is any amino acid, have a high propensity to interact non-covalently with SUMOylated proteins [27-30]. An inverse SIM (amino acids 266-VVRV-269) was found in Oct4 (Figure 6a). Importantly, when this SIM was mutated in Oct4 (Oct4- $\triangle$ SIM), the interaction with ESET was abrogated (Figure 6b, lane 2). This result shows that the SIM of Oct4 is crucial for SUMOylated ESET-Oct4 interaction. The precise nature of this interaction remains to be elucidated.

We then considered if the SIM of Oct4 is functional in the repression of $C d x 2$. We investigated this possibility by substituting the endogenous Oct4 in ZHBTc4 ES cells with exogenous Oct $4-\Delta$ SIM. Since the SIM of Oct4 is critical for the interaction with ESET, we anticipated that $C d x 2$ repression would be less effective in cells that express Oct4- $\Delta$ SIM compared to cells that express wild-type Oct4. Indeed, this was the case. In control ZHBTc4 ES cells treated with tetracycline, $C d x 2$ was upregulated concomitant with the depletion of Oct4 (Figure 6c, lane 2). When these cells were supplied with exogenous Oct4 (Figure 6c, lane 3), the upregulation of $C d x 2$ was also impeded even though the level of transiently expressed exogenous Oct4 was on average about $10 \%$ of the endogenous level in untreated ES cells (Figure 6c, middle panel). However, when Oct4- $\Delta$ SIM was supplied instead of wild-type Oct4 (Figure 6c, lane 4) at a comparable level, $C d x 2$ expression was elevated, notably to a level that approaches the $C d x 2$ expression levels induced by the lack of Oct4 (Figure 6c, lane 2). This suggests that the difference in the outcome of response to Oct 4 or Oct $4-\Delta S I M$ on the repression of $C d x 2$ in the ES cells, might be due to the nature of the repressor complexes that it recruits through its SIM, as Oct4- $\Delta$ SIM is able to bind DNA (Additional file 7). It is possible that Oct4 may interact with SUMOylated ESET through the subunits of the transcriptional repression complexes such as HDAC2 [31,32]. We note that Gata6, a primitive endoderm-specific gene, as well as Hand1 and Dlx3 that were upregulated in Eset knockdown ES cells (Figure 1d), were similarly repressed by Oct4 and resistant to repression by Oct4- $\Delta$ SIM (Additional file 7 ). These data suggest that SUMOylated ESET-Oct4 complex may act to repress genes other than $C d x 2$. It is equally likely that ESET might interact with other transcription factors to repress a different subset of genes in ES cells. Further work is also required to delineate how Oct4 functions in ES cells to discriminate between its role both as an activator, and as a repressor of genes through ESET-Oct4 complex.

\section{Conclusion}

We have uncovered an important epigenetic mechanism that maintains pluripotency by preventing differentiation of ES cells, notably into trophectoderm cells. The Oct4ESET mediated H3K9me3 epigenetic modification involved in the repression of $C d x 2$ may affect other genes, including Gata6, to underpin pluripotency. The synergistic action of Oct4 and ESET could also explain the previously described observation that Oct4 regulates expression of $C d x 2$ [12]. The SIM of Oct4 is apparently critical for the interaction of ESET and Oct4, which highlights the importance of this motif in forming an effective SUMOylated ESET-Oct4 repressive complex. Since ESET, like Oct4 is a maternally inherited protein in the oocyte [8], they may also be critical for the establishment of 


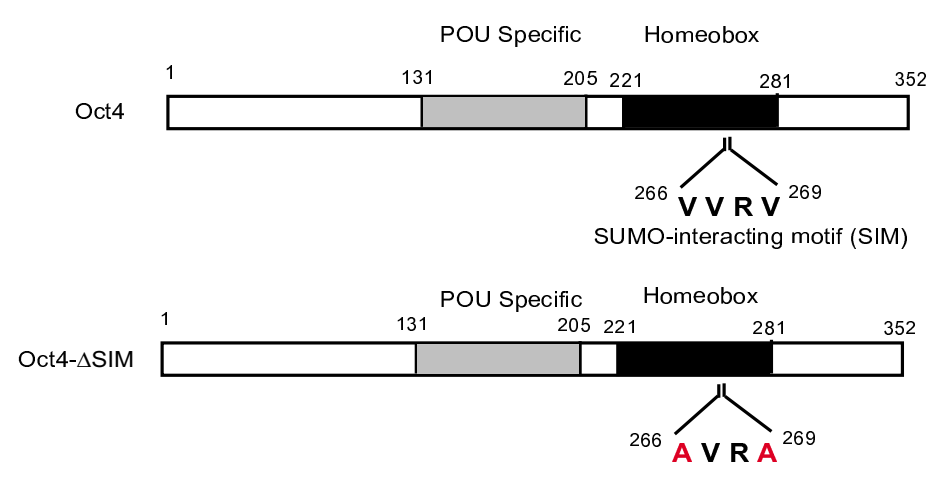

b

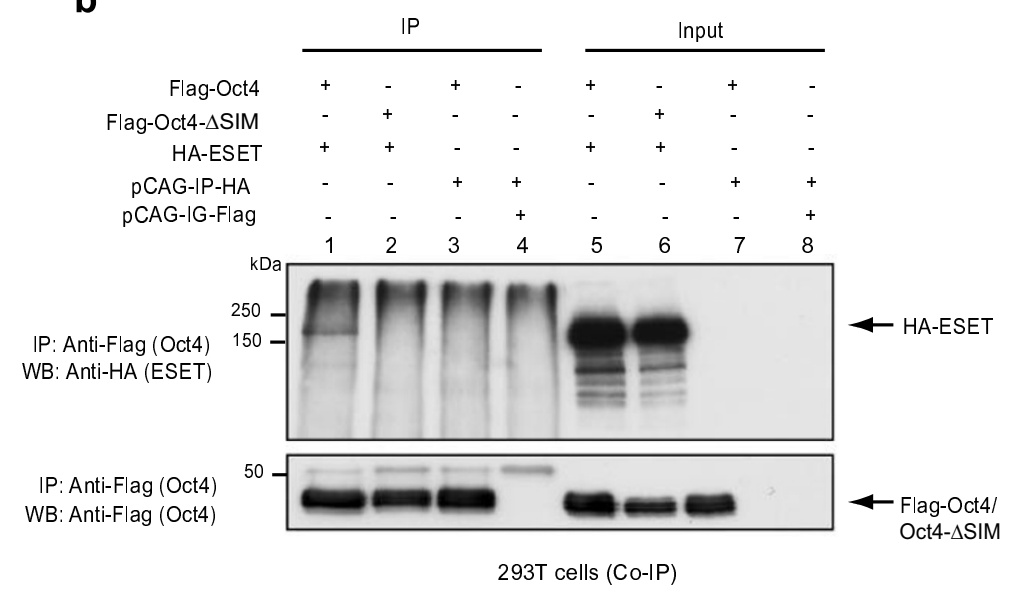

C

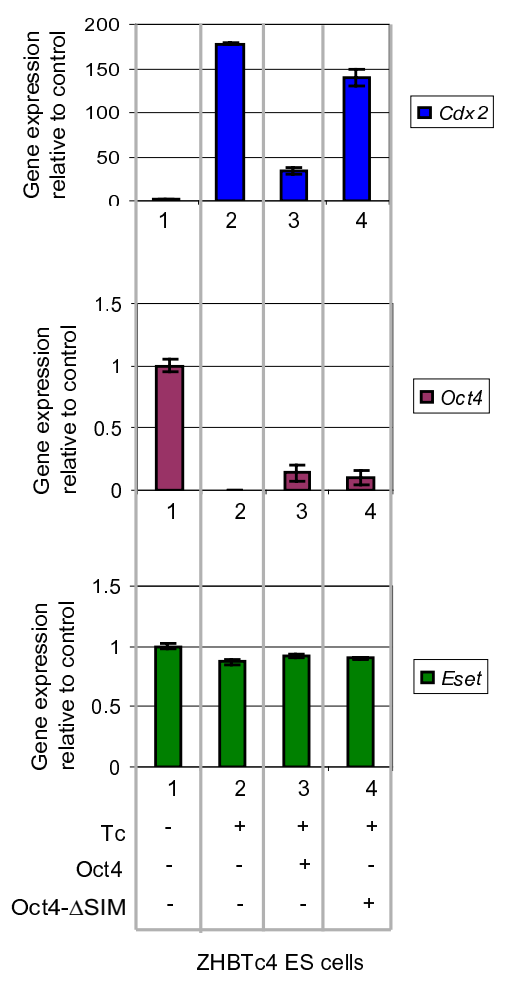

\section{Figure 6}

Small ubiquitin-related modifier (SUMO)-interacting motif (SIM) of Oct4 is crucial for the interaction with ERG-associated protein with SET domain (ESET) and the repression of Cdx2. (a) Figure depicts SIM in Oct4 (top panel) and the mutations (red alphabet) in the Oct4-lacking SIM (- $\Delta$ SIM) (bottom panel). (b) Expression vectors indicated were transfected in 293T cells and immunoprecipitant (IP) from anti-Flag antibody and input were subjected to western blot (WB) with anti-haemagglutinin (HA) (ESET, top panel) and anti-Flag (Oct4 or Oct4- $\Delta$ SIM, bottom panel) antibodies. (c) Quantitative polymerase chain reaction (Q-PCR) analysis of Cdx2 (top), Oct4 (middle) and Eset (bottom) in ZHBTc4 ES cells that were either non-treated or treated with tetracycline $(\mathrm{Tc})$ to deplete the endogenous Oct4 and transfected with the indicated plasmids, relative to control embryonic stem (ES) cells which was set as I.0 (lane I) after normalising against Gapdh. An empty vector was used as a transfection control in lane 2. Error bars represent standard deviation (SD) of the average and median of four different fractions of cells of different green fluorescent protein (GFP) intensity except for control ES cells (lane I) where error bar represents the SD of three technical replicates.

pluripotent cells in the ICM, at least in part through repression of $C d x 2$ (Figure 7). Notably, the loss of ESET or Oct4 results in the loss of the pluripotent ICM $[8,9]$. Furthermore, disruption of the SUMO pathway by the inactivation of the SUMO E2-conjugating enzyme $U b c 9$ is detrimental to the development of the ICM [33]. The use of a conditional allele of Eset will address the precise developmental role of this gene in the future. SUMOylated ESET-Oct4 interaction is probably pivotal for both the establishment of pluripotency in the ICM and its maintenance in ES cells.

\section{Methods}

\section{RNAi constructs and transfection}

shRNA oligonucleotides were cloned into the BglII and HindIII sites of the pSuper.puro vector (Oligoengine, Seattle, WA, USA). Sequences for Eset shRNA which has been described previously [5] are 5'GATCCCCGATGTGAGTGGATATATCGTTCAAGAGAC- 


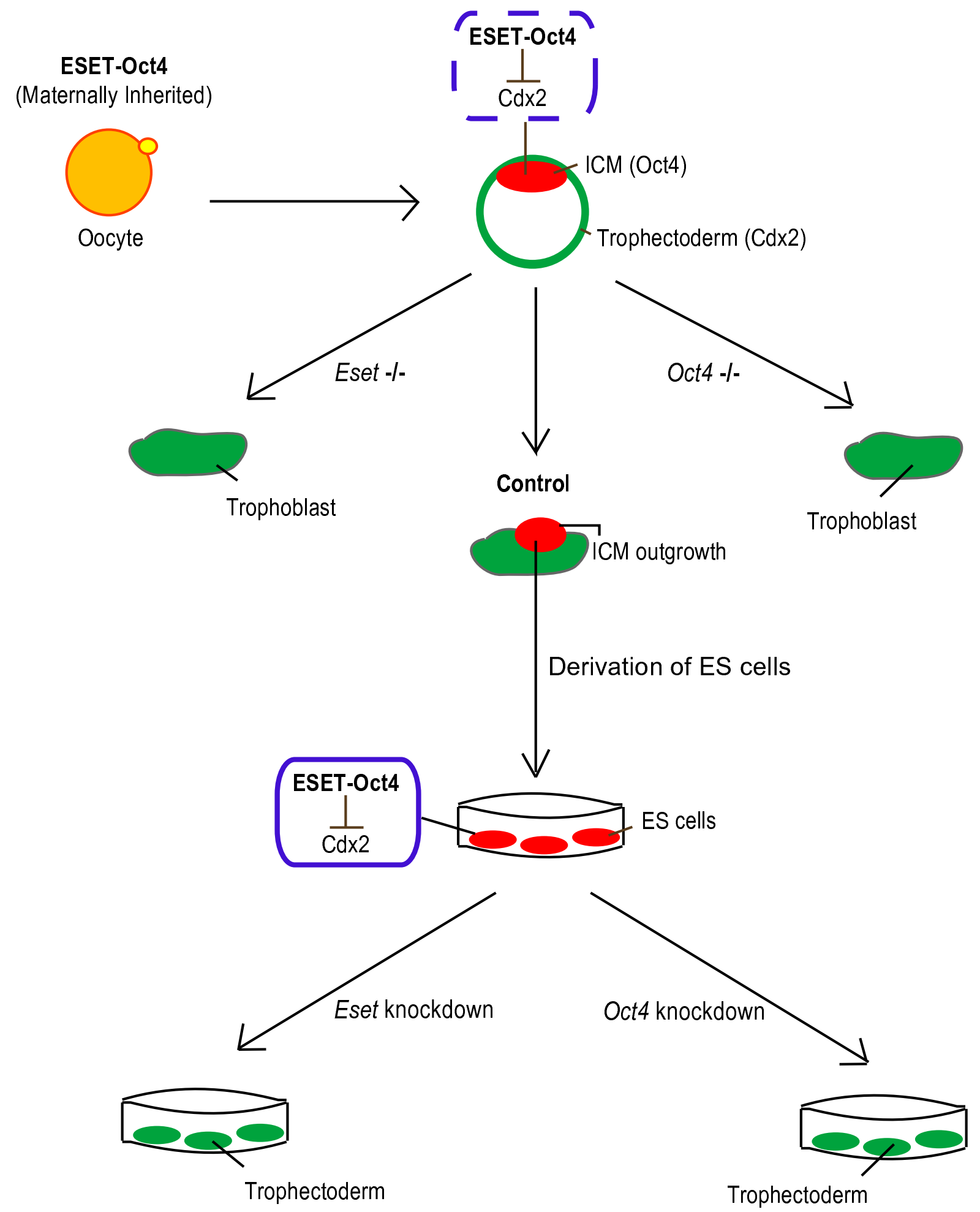

Figure 7

The proposed model of the establishment of pluripotent cells in the inner cell mass (ICM) through the repression of Cdx2 by ERG-associated protein with SET domain (ESET)-Oct4 complex. 

$\begin{array}{ll}\text { GATATATCCACTCACATCTTTTTA-3' } & \text { and } \\ \text { AGCTTAAAAAGATGTGAGTGGATATATCGTCTCTT- } & \end{array}$ GAACGATATATCCACTCACATCGGG-3'. Sequences for Pml shRNA which has also been described previously [34] are 5'-GATCCCCGCGCAAGTCCAATATCTTCTTCAAGAGAGAAGATATTGGACTTGCGCTTTTTA-3' and 5'AGCTTAAAAAGCGCAAGTCCAATATCTTCTCTCTTGAAGAAGATATTGGACTTGCGCGGG-3'.

For construction of shRNA-poliovirus internal ribosomal entry site (pIRES)-EGFP, pSuper.puro with or without shRNA insert that has been digested with NotI and HincII were ligated to pIRES-EGFP (Clontech, Mountain View, CA, USA) that has been digested with NruI and NotI. For transfection, $0.5 \times 10^{6}$ ES cells plated in 1 well of a 6 -well plate and cultured overnight were transfected with $3 \mu \mathrm{g}$ of plasmid using Lipofectamine 2000 reagent (Invitrogen, Carlsbad, CA, USA). Transfected cells were selected with 1 $\mu \mathrm{g} / \mathrm{ml}$ puromycin (Sigma, St Louis, MO, USA) starting from $24 \mathrm{~h}$ after transfection and cells were passaged upon reaching confluency. For alkaline phosphatase staining, western blot and analysis of the gene expression by QPCR, cells were harvested on the indicated days without undergoing fluorescence sorting. For morphology visualisation, immunostaining and carrier ChIP analysis, transfected cells were first sorted by FACS either 1 day (for morphology visualisation) or 3 days after transfection. For Pml knockdown experiments, immunostaining was performed at day 5 after transfection and immunoprecipitation was performed at day 4 after transfection.

\section{Cell culture}

Undifferentiated ES cells were cultured without feeders on gelatin-coated culture dish in Dulbecco's modified Eagle medium/F12 nutrient mixture without l-glutamine (DMEM/F12) (Gibco, Carlsbad, CA, USA) supplemented with 20\% foetal bovine serum (Gibco, Carlsbad, CA, USA), 2 mM l-glutamine (Gibco, Carlsbad, CA, USA), 0.1 mM minimal essential medium (MEM) with non-essential amino acids (Gibco, Carlsbad, CA, USA), $100 \mathrm{U} / \mathrm{ml}$ penicillin and $0.1 \mathrm{mg} / \mathrm{ml}$ streptomycin (Gibco, Carlsbad, CA, USA), $1 \mathrm{mM}$ sodium pyruvate (Sigma, St Louis, MO, USA), $0.12 \%$ sodium bicarbonate solution (Sigma, St Louis, MO, USA), $50 \mu \mathrm{M}$ 2-mercaptoethanol (Gibco, Carlsbad, CA, USA), $0.15 \mathrm{mM}$ of each nucleoside comprising adenosine, cytidine, guanosine and uridine and $0.05 \mathrm{mM}$ of thymidine (Sigma, St Louis, MO, USA) and $2000 \mathrm{U} / \mathrm{ml}$ leukaemia inhibitory factor (Chemicon, Billerica, MA, USA). ZHBTc4 ES cell cultures were as described previously [18]. Oct4 expression was regulated by the addition of $1 \mu \mathrm{g} / \mathrm{ml}$ doxycycline (Sigma, St Louis, $\mathrm{MO}, \mathrm{USA}$ ) to the culture medium. TS cultures were as described previously [13].

\section{RNA extraction and real-time Q-PCR}

Total RNA was prepared using RNeasy Mini Kit (Qiagen, Hilden, Germany) and cDNA was synthesised from $1 \mu \mathrm{g}$ of RNA using SuperScript III reverse transcriptase (Invitrogen, Carlsbad, CA, USA). Endogenous mRNA levels were measured by Q-PCR based on SYBR Green detection with the ABI Prism 7000 PCR machine (Applied Biosystems, Foster City, CA, USA). Each reaction in a total volume of $20 \mu \mathrm{l}$ contained $1 \mu \mathrm{l}$ of $10 \times$ diluted cDNA, $1 \mu \mathrm{M}$ of forward and reverse primer and $1 \times$ QuantiTect SYBR Green Master Mix reagent (Qiagen, Hilden, Germany). Standard curves for each primer were performed in the same sample plate to determine the relative quantification of the transcript. Q-PCR was performed in triplicates and normalised with Gapdh, a housekeeping gene. The data were then normalised against vector control or untreated ES cells which were defined as $100 \%$ or 1.0 . Each experiment was performed independently on at least two occasions. Sequences of primers used for Q-PCR are available in Additional file 8.

\section{Protein extraction and immunoblot}

Cell lysate was extracted using cold radioimmunoprecipitation assay (RIPA) buffer consisting $50 \mathrm{mM}$ tris(hydroxymethyl)aminomethane (Tris) $\mathrm{pH} 8.0,150$ $\mathrm{mM} \mathrm{NaCl}, 1 \% \mathrm{NP} 40,0.5 \%$ sodium deoxycholate and $0.1 \%$ sodium dodecyl sulfate (SDS) added with protease inhibitors (Roche, Basel, Switzerland) for $30 \mathrm{~min}$ on ice, followed by centrifugation at 13,000 rpm for $30 \mathrm{~min}$. Supernatant was collected and protein concentration was measured by Bradford assay (Sigma, St Louis, MO, USA). Total protein (20 to $30 \mu \mathrm{g}$ ) was separated by Tris-glycine SDS polyacrylamide gel and transferred to Hybond-P poly(vinylidene difluoride) (PVDF) (Amersham, Buckinghamshire, UK) membrane. Proteins on polyacrylamide gel were visualised by staining with Imperial Protein Stain (Pierce, Waltham, MA, USA).

\section{Cotransfection and immunoprecipitation}

Full details on vector constructions are available in Additional file 9. For cotransfection experiments, $3.5 \times 10^{6}$ $293 \mathrm{~T}$ cells plated on a $10 \mathrm{~cm}$ dish and cultured overnight were transfected with $18 \mu \mathrm{g}$ of DNA comprising of $9 \mu \mathrm{g}$ of two different constructs with Lipofectamine 2000 reagent (Invitrogen, Carlsbad, CA, USA). Cells were harvested for immunoprecipitation $48 \mathrm{~h}$ after transfection. Cells were washed twice in cold phosphate-buffered saline (PBS) and scraped into $1 \mathrm{ml}$ of PBS. Cell pellet were resuspended in $200 \mu \mathrm{l}$ of immunoprecipitation buffer (50 mM Tris $\mathrm{pH}$ $7.5,150 \mathrm{mM} \mathrm{NaCl}, 5 \mathrm{mM}$ ethylenediaminetetraacetic acid

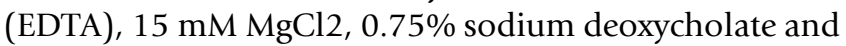
$1 \%$ NP40 added with protease inhibitors from Roche, Basel, Switzerland), incubated on ice for $30 \mathrm{~min}$ and centrifuged at $13,000 \mathrm{rpm}$ for $30 \mathrm{~min}$ at $4^{\circ} \mathrm{C}$. A total of 100 $\mu \mathrm{l}$ of the supernatant was then diluted with $900 \mu \mathrm{l}$ dilu- 
tion buffer (50 mM Tris $\mathrm{pH} 7.5$ and $150 \mathrm{mM} \mathrm{NaCl}$ added with protease inhibitor from Roche, Basel, Switzerland) so that the final concentration of NP40 in the immunoprecipitation reaction was $0.1 \%$. The primary antibody was incubated with the protein lysate at $4{ }^{\circ} \mathrm{C}$ overnight. Precipitation was performed by adding $50 \mu$ l of Dynabeads Protein G (Invitrogen, Carlsbad, CA, USA) to the reaction for $1 \mathrm{~h}$ followed by five washes in buffer containing $50 \mathrm{mM}$ Tris $\mathrm{pH} 8.0,150 \mathrm{mM} \mathrm{NaCl}$ and $0.1 \% \mathrm{NP} 40$. Beads were boiled for 5 min with $50 \mu \mathrm{l} 2 \times$ Laemmli sample buffer (Bio-Rad, Hercules, CA, USA) and $20 \mu \mathrm{l}$ of the supernatant were subjected to western blot. Where indicated, lysis buffer was also added with $20 \mathrm{mM}$ NEM (Sigma, St Louis, MO, USA) and 1:100 diluted phosphatase inhibitors I and II (Sigma, St Louis, MO, USA).

\section{Endogenous immunoprecipitation}

To analyse SUMOylated ESET, one confluent $10 \mathrm{~cm}$ dish of ES cells was lysed in $100 \mu \mathrm{l}$ buffer containing $50 \mathrm{mM}$ Tris pH 7.5, $150 \mathrm{mM} \mathrm{NaCl}, 5 \mathrm{mM}$ EDTA, $15 \mathrm{mM} \mathrm{MgCl2,}$ $0.75 \%$ sodium deoxycholate, 1\% NP40 supplemented with protease inhibitors (Roche, Basel, Switzerland), 1:100 diluted phosphatase inhibitors I and II (Sigma, St Louis, MO, USA) and 20 mM NEM (Sigma, St Louis, MO, USA). Where indicated, lysis buffer was also added with $50 \mu \mathrm{g} / \mathrm{ml}$ of ethidium bromide. Cell lysate was incubated on ice for $30 \mathrm{~min}$ and centrifuged at 13,000 rpm for 30 $\min$ at $4^{\circ} \mathrm{C}$. A total of $100 \mu \mathrm{l}$ of the supernatant were then diluted with $900 \mu \mathrm{l}$ dilution buffer (50 mM Tris pH 7.5 and $150 \mathrm{mM} \mathrm{NaCl}$ added with the protease inhibitors (Roche, Basel, Switzerland), 1:100 diluted phosphatase inhibitors I and II (Sigma, St Louis, MO, USA) and $20 \mathrm{mM}$ NEM (Sigma, St Louis, MO, USA). Cell lysate was precleared with $25 \mu \mathrm{l}$ Dynabeads Protein G (Invitrogen, Carlsbad, CA, USA) for $1 \mathrm{~h}$ at $4^{\circ} \mathrm{C}$ and centrifuged at $13,000 \mathrm{rpm}$ for $20 \mathrm{~min}$ at $4^{\circ} \mathrm{C}$. The primary antibody was incubated with the supernatant at $4^{\circ} \mathrm{C}$ overnight. Precipitation was performed by the addition of $50 \mu$ of Dynabeads Protein $\mathrm{G}$ to the reaction for $1 \mathrm{~h}$ followed by five washes in immunoprecipitation buffer as described above. Beads were resuspended in $35 \mu \mathrm{l}$ of immunoprecipitation buffer and $45 \mu$ l of $2 \times$ Laemmli sample buffer (Bio-Rad, Hercules, CA, USA). After boiling for $5 \mathrm{~min}, 20$ $\mu \mathrm{l}$ of the supernatant were subjected to western blot using $4 \%$ to $15 \%$ Tris- $\mathrm{HCl}$ gradient gel (Bio-Rad, Hercules, CA, USA). For immunoprecipitation in mild conditions (where indicated), lysis and immunoprecipitation buffer consist of $50 \mathrm{mM}$ Tris- $\mathrm{HCl} \mathrm{pH} \mathrm{7.5,} 150 \mathrm{mM} \mathrm{NaCl}$ and $0.3 \%$ digitonin (Sigma, St Louis, MO, USA) supplemented with protease inhibitors (Roche, Basel, Switzerland), 1:100 diluted phosphatase inhibitors I and II (Sigma, St Louis, MO, USA) and 20 mM NEM (Sigma, St Louis, MO, USA). Wash buffer consists of the same components as immunoprecipitation buffer except that 50 $\mathrm{mM} \mathrm{NaCl}$ was used.

\section{Chromatin immunoprecipitation}

Chromatin immunoprecipitation was performed according to a published protocol [35] with some modifications. Briefly, cells were crosslinked with 1/10 volume of fresh $11 \%$ formaldehyde solution for $15 \mathrm{~min}$ and quenched with $1 / 20$ volume of $2.5 \mathrm{M}$ glycine. Cells were sonicated to an average of 500 base pairs (bp) and immunoprecipitated overnight with antibody that was preincubated with $100 \mu$ l Dynabeads M-280 Sheep Anti-Rabbit (Invitrogen, Carlsbad, CA, USA) overnight. For isolation of DNA, 100 $\mu \mathrm{l}$ of $10 \%$ Chelex $(\mathrm{w} / \mathrm{v})$ was added to the washed beads, vortexed and boiled for $10 \mathrm{~min}$ [36]. After cooling to room temperature, $100 \mu \mathrm{g} / \mathrm{ml}$ of proteinase $\mathrm{K}$ was added and beads were incubated for $30 \mathrm{~min}$ at $55^{\circ} \mathrm{C}$ in a shaking block. Beads were boiled for another $10 \mathrm{~min}$, centrifuged, and the supernatant was collected. The Chelex/bead fraction was vortexed with another $100 \mu$ of water, centrifuged and the supernatant collected was combined with the first supernatant. Immunoprecipitated DNA (3 $\mu \mathrm{l})$ was used as template for PCR amplification with Red Taq (Sigma, St Louis, MO, USA) or 1 to $2 \mu \mathrm{l}$ was used for QPCR analysis using $1 \times$ QuantiTect SYBR Green Master Mix reagent (Qiagen, Hilden, Germany). Data were normalised to the input or H3 ChIP, control IgG and the least enriched region (as indicated in the figure legends). To compare the enrichment of H3K9me3 between samples, carrier ChIP was performed by adding $3 \times 10^{7} 293 \mathrm{~T}$ cell to $1 \times 10^{6}$ FACS-sorted, EGFP-positive ES cells transfected with either Eset shRNA or empty vector for 3 days (selected with puromycin for 2 days). Carrier ChIP of H3K9me3 was also performed in Figure 3d. Immunoprecipitated DNA was concentrated by ethanol precipitation before PCR analysis. Data were normalised against the input and relative to the controls. Semi quantification of band intensity was performed using Quantity One software (Bio-Rad, Hercules, CA, USA). ChIP experiments were performed independently on at least two occasions. Primers and PCR conditions for ChIP are available in Additional file 10.

\section{Mutagenesis and transfection}

Oct4- $\Delta$ SIM construct was generated using the QuikChange XL Site-Directed Mutagenesis Kit (Stratagene, La Jolla, CA, USA). Details on the construct are available in Additional file 9. For transfection, $0.5 \times 10^{6}$ ZHBTc4 ES cells plated on 1 well of a 6 -well plate and cultured overnight were transfected with $3 \mu \mathrm{g}$ of plasmid using Lipofectamine 2000 reagent (Invitrogen, Carlsbad, CA, USA). Doxycycline $1 \mu \mathrm{g} / \mathrm{ml}$ (Sigma, St Louis, MO, USA) was added to the culture medium after $6 \mathrm{~h}$ of transfection to remove the endogenous Oct4. Transfected cells were sorted by FACS after 48 h of transfection. 


\section{Immunofluorescence microscopy}

Single cells on poly-l-lysine (Sigma, St Louis, MO, USA) treated 12 well microscope slides (Erie Scientific Company, Waltham, MA, USA) were centrifuged at 1,000 rpm for $1 \mathrm{~min}$ and fixed with 4\% paraformaldehyde (Sigma, St Louis, MO, USA) in PBS for $15 \mathrm{~min}$. This was followed by three washes in PBS and blocking and permeabilisation in $0.1 \%$ Triton $\mathrm{X}(\mathrm{v} / \mathrm{v})$ and $1 \%$ bovine serum albumin (BSA) $(\mathrm{w} / \mathrm{v})$ in PBS for $30 \mathrm{~min}$. Primary antibodies diluted in blocking buffer were incubated at $4{ }^{\circ} \mathrm{C}$ overnight. Secondary antibodies conjugated to Alexa Fluor 488 and 568 (Molecular Probes, Carlsbad, CA, USA) and DAPI ( $1 \mu \mathrm{g} /$ $\mathrm{ml})$ were incubated at room temperature, in the dark for $1 \mathrm{~h}$. Cells were mounted on slides with Vectashield (Vector Laboratories, Burlingame, CA, USA) containing DAPI and images were captured with a Bio-Rad Radiance 2000 confocal microscope.

\section{Antibodies}

Antibodies used for western blot were; ESET (07-378, Upstate, Billerica, MA, USA), $\alpha$-tubulin (T9026, Sigma, St Louis, MO, USA), H3K9me3 (07-442, Upstate, Billerica, MA, USA), H3K4me2 (ab7766, Abcam, Cambridge, UK), Oct-3 (611202, BD, Franklin Lakes, NJ, USA), Cdx2 (Biogenex, San Ramon, CA, USA), SUMO-1 (Affinity Bioreagents, Waltham, MA, USA), PML (05-718, Upstate, Billerica, MA, USA) Anti-Flag (F3165, Sigma, St Louis, MO, USA) and Anti-HA (ab9110; Abcam, Cambridge, UK). Antibodies used for immunoprecipitation were; ESET (ab12317, Abcam, Cambridge, UK), (kind gift from $\mathrm{HH} \mathrm{Ng}$, Genome Institute of Singapore, Singapore) and (sc-46110, Santa Cruz, Santa Cruz, CA, USA), SUMO-1 (Affinity Bioreagents, Waltham, MA, USA), PML (sc-5621, Santa Cruz, Santa Cruz, CA, USA), Oct4 (sc-9081, Santa Cruz, Santa Cruz, CA, USA), Anti-Flag (F3165, Sigma, St Louis, MO, USA) and Anti-HA (ab9110; Abcam, Cambridge, UK).

Antibodies used for chromatin immunoprecipitation were; H3K9me3 (ab8898; Abcam, Cambridge, UK), ESET (kind gift from $\mathrm{HH} \mathrm{Ng}$, Genome Institute of Singapore), Oct4 (sc-9081, Santa Cruz, Santa Cruz, CA, USA), SUMO1 (Zymed, Carlsbad, CA, USA), Anti-Flag (F3165, Sigma, St Louis, MO, USA) and Anti-HA (ab9110; Abcam, Cambridge, UK). Antibodies used for immunofluorescence were Cdx2 (1:100, Biogenex, San Ramon, CA, USA), ESET (1:100, 07-378, Upstate, Billerica, MA, USA) and PML (1:200, 05-718, Upstate, Billerica, MA, USA).

\section{Competing interests}

The authors declare that they have no competing interests.

\section{Authors' contributions}

L-SY, KH and MAS were involved in project planning and data analysis. L-SY performed experimental work. L-SY and MAS wrote the manuscript.

\section{Additional material}

\section{Additional file 1}

Eset is required for normal embryonic stem (ES) cell phenotype. (a) Alkaline phosphatase staining of Eset knockdown (right panel) and control (left panel) ES cells after 7 days of short hairpin RNA (shRNA) transfection. Scale bar, $100 \mu \mathrm{m}$. (b) Morphology of Eset knockdown and control ES cells after 3 days of shRNA transfection from both EGFP-positive (transfected) and EGFP-negative (untransfected) populations. Scale bar, $100 \mu \mathrm{m}$. Inset, $50 \mu \mathrm{m}$.

Click here for file

[http://www.biomedcentral.com/content/supplementary/17568935-2-12-S1.PDF]

\section{Additional file 2}

ERG-associated protein with SET domain (ESET)-mediated histone 3 lysine 9 trimethylation (H3K9me3) represses $\mathrm{Cdx} 2$ in embryonic stem (ES) cells. (a) Semiquantitative polymerase chain reaction (PCR)-chromatin immunoprecipitation (ChIP) analysis of H3K9me3 at the $\mathrm{Cdx} 2$ and Oct 4 promoter regions in ES cells. (b) Carrier ChIP semiquantitative PCR analysis of H3K9me3 in fluorescence-activated cell sorting (FACS)sorted Eset knockdown ES cells (+) and control ES cells (-). 293T cells were added as carrier. $\mathrm{H} 3 \mathrm{~K} 9 \mathrm{me} 3 \mathrm{l}$ levels were downregulated at the $\mathrm{Cdx} 2$ promoter region (top panel, lane 4). No signal was detected in carrier cells, 293 T input (lane 7) showing specificity of PCR to mouse genomic DNA. Primers C6 and C7 were not specific to mouse DNA. H3K9me3 was not detected at the control Oct4 promoter region (middle panel). Suv39h1/2-mediated H3K9me3 level at the major satellite region was unaffected in ESET-depleted ES cells (bottom panel).

Click here for file

[http://www.biomedcentral.com/content/supplementary/17568935-2-12-S2.PDF]

\section{Additional file 3}

ERG-associated protein with SET domain (ESET) binding to Cdx2 promoter is dependent on Oct4 through Oct4-ESET interaction. (a) Quantitative polymerase chain reaction (Q-PCR) analysis of the levels of haemagglutinin (HA)-ESET enrichment at region $\mathrm{C} 7$ of the $\mathrm{Cd} 22$ promoter in ZHBTc4 embryonic stem (ES) cells, which were first treated with tetracycline, followed 1 day later by transfection of HA-ESET. At 1 day after transfection (day 2 of tetracycline treatment), cells were harvested for ChIP experiments. HA-ESET enrichment on day 2 of tetracycline treatment is relative to untreated cells after normalising against ZHBTc4 ES cells transfected with an empty vector, and their respective input. Error bars, standard deviation (SD) of three technical replicates. (b) Coimmunoprecipitation of ESET with Oct4 in $293 \mathrm{~T}$ cells. Expression vectors indicated were transfected and Flag-tagged Oct4 protein was

immunoprecipitated. Immunoprecipitant (IP) and supernatant were subjected to western blot (WB) with anti-HA (ESET, top panel) and antiFlag (Oct4, bottom panel) antibodies. HA, haemagglutinin. (c) Drawings depicting full length ESET and ESET mutant proteins. Numbers indicate amino acids. (d) Coimmunoprecipitation of ESET- $S$ SET and ESET$\Delta T u d o r$ with Oct4 in $293 T$ cells. Expression vectors indicated were transfected and Flag-tagged Oct4 protein was immunoprecipitated. Click here for file

[http://www.biomedcentral.com/content/supplementary/17568935-2-12-S3.PDF] 


\section{Additional file 4}

Interaction of small ubiquitin-related modifier (SUMO) ylated ERGassociated protein with SET domain (ESET) and Oct4 is DNA independent. (a) Embryonic stem (ES) cell lysates were immunoprecipitated (IP) with anti-ESET antibody (kind gift of $\mathrm{HH} \mathrm{Ng}$; see text) under mild conditions in digitonin-containing buffer in the presence of $50 \mu \mathrm{g} / \mathrm{ml}$ ethidium bromide and subjected to western blotting (WB) with the antibodies indicated. Rabbit IgG was used as a negative control. (b) ES cell lysates were immunoprecipitated (IP) with the indicated antibodies in buffer containing NP40 and N-ethylmaleimide either in the presence or absence of $50 \mu \mathrm{g} / \mathrm{ml}$ ethidium bromide and subjected to WB using $4 \%$ to $15 \%$ Tris-HCl gradient gel. A rabbit anti-haemagglutinin (HA) antibody was used as a negative control.

Click here for file

[http://www.biomedcentral.com/content/supplementary/17568935-2-12-S4.PDF]

\section{Additional file 5}

ERG-associated protein with SET domain (ESET) interacts with promyelocytic leukaemia (PML). (a) Coimmunoprecipitation of PML with ESET in $293 T$ cells. Immunoprecipitant (IP) and supernatant were subjected to western blot (WB) with anti-Flag (PML, top panel) and antihaemagglutinin (HA) (ESET, bottom panel) antibodies. (b) Embryonic stem (ES) cell lysates were immunoprecipitated (IP) with the indicated antibodies in buffer containing NP40 in the presence of N-ethylmaleimide (NEM) and subjected to WB using 4\% to $15 \%$ Tris-HCl gradient gel. A rabbit anti-HA antibody was used as a negative control.

Click here for file

[http://www.biomedcentral.com/content/supplementary/17568935-2-12-S5.PDF]

\section{Additional file 6}

Putative small ubiquitin-related modifier (SUMO)ylation sites of ERG-associated protein with SET domain (ESET) based on the SUMOplot software. Red triangles represent motifs with high probability and blue triangles represent motifs with low probability.

Click here for file

[http://www.biomedcentral.com/content/supplementary/17568935-2-12-S6.PDF]

\section{Additional file 7}

Mutation of Oct4 SIM does not affect its ability to bind DNA. (a) Quantitative polymerase chain reaction (Q-PCR) analysis of the levels of Flag-tagged enrichment at region $\mathrm{O} 1$ of the Oct4 promoter in ZHBTc4 ES cells transfected with Flag-Oct4 or Flag-Oct4-4SIM relative to controls transfected with an empty vector after normalising against their respective input. Tetracycline was added to the culture medium $6 \mathrm{~h}$ after transfection to deplete endogenous Oct4. Cells were harvested at 48 h after transfection. Error bars, standard deviation (SD) of three technical replicates. (b) Q-PCR analysis of Gata6 (top), Dlx3 (middle) and Hand1 (bottom) in ZHBTc4 embryonic stem (ES) cells; these cells were treated with tetracycline (Tc+) to deplete the endogenous Oct4, or left untreated (Tc-). They were transfected with the indicated control or mutant Oct4 plasmids.

Gene expression levels are relative to control ES cells which was set as 1.0 (lane 1) after normalising against Gapdh. An empty vector was used as a transfection control in lane 2. Error bars represent SD of the average and median of four different fractions of cells of different GFP intensity except for control ES cells (lane 1) where error bar represents the SD of three technical replicates.

Click here for file

[http://www.biomedcentral.com/content/supplementary/17568935-2-12-S7.PDF]

\section{Additional file 8}

Table S1. Quantitative polymerase chain reaction (Q-PCR) Primers Click here for file

[http://www.biomedcentral.com/content/supplementary/17568935-2-12-S8.DOC]

\section{Additional file 9}

Supplementary methods. Overexpression constructs Click here for file

[http://www.biomedcentral.com/content/supplementary/17568935-2-12-S9.DOC]

\section{Additional file 10}

Table S2. Chromatin Immunoprecipitation (ChIP) Primers Click here for file

[http://www.biomedcentral.com/content/supplementary/17568935-2-12-S10.DOC]

\section{Acknowledgements}

We thank B Lim and WL Tam for shRNA constructs, HH Ng for the ESET antibody, A Smith for the ZHBTc4 cells, S Bao for assistance in embryology experiments, D Griffiths for advice on ChIP and M Johnson, P Hajkova and $F$ Tang for critical reading of the manuscript. L-SY was a recipient of the BBSRC-Dorothy Hodgkin Postgraduate Award. This work was supported by grants from Wellcome Trust to MAS.

\section{References}

I. Schultz DC, Ayyanathan K, Negorev D, Maul GG, Rauscher FI III: SETDB I: a novel KAP-I-associated histone $\mathrm{H3}$, lysine 9-specific methyltransferase that contributes to HPI-mediated silencing of euchromatic genes by KRAB zinc-finger proteins. Genes Dev 2002, 16:919-932.

2. Yang L, Xia L, Wu DY, Wang H, Chansky HA, Schubach WH, Hickstein DD, Zhang Y: Molecular cloning of ESET, a novel histone H3-specific methyltransferase that interacts with ERG transcription factor. Oncogene 2002, 21:148-152.

3. Blackburn ML, Chansky HA, Zielinska-Kwiatkowska A, Matsui Y, Yang L: Genomic structure and expression of the mouse ESET gene encoding an ERG-associated histone methyltransferase with a SET domain. Biochim Biophys Acta 2003, 1629:8-14.

4. Yang L, Mei Q, Zielinska-Kwiatkowska A, Matsui Y, Blackburn ML, Benedetti D, Krumm AA, Taborsky GJ Jr, Chansky HA: An ERG (ets-related gene)-associated histone methyltransferase interacts with histone deacetylases $\mathrm{I} / 2$ and transcription corepressors mSin3A/B. Biochem J 2003, 369:65I-657.

5. Wang $H, A n W$, Cao R, Xia L, Erdjument-Bromage $H$, Chatton $B$, Tempst $P$, Roeder RG, Zhang Y: mAM facilitates conversion by ESET of dimethyl to trimethyl lysine 9 of histone $\mathrm{H} 3$ to cause transcriptional repression. Mol Cell 2003, I 2:475-487.

6. Sarraf SA, Stancheva I: Methyl-CpG binding protein MBDI couples histone $\mathrm{H} 3$ methylation at lysine 9 by SETDB I to DNA replication and chromatin assembly. Mol Cell 2004, 15:595-605.

7. Li H, Rauch T, Chen Z-X, Szabo PE, Riggs AD, Pfeifer GP: The histone methyltransferase SETDB I and the DNA methyltransferase DNMT3A interact directly and localize to promoters silenced in cancer cells. J Biol Chem 2006, 28 I: $19489-19500$.

8. Dodge JE, Kang Y-K, Beppu H, Lei H, Li E: Histone H3-K9 methyltransferase ESET is essential for early development. Mol Cell Biol 2004, 24:2478-2486.

9. Nichols J, Zevnik B, Anastassiadis K, Niwa H, Klewe-Nebenius D, Chambers I, Scholer H, Smith A: Formation of pluripotent stem cells in the mammalian embryo depends on the POU transcription factor Oct4. Cell 1998, 95:379-391.

10. Hay DC, Sutherland L, Clark J, Burdon T: Oct-4 knockdown induces similar patterns of endoderm and trophoblast differ- 
entiation markers in human and mouse embryonic stem cells. Stem Cells 2004, 22:225-235.

11. Beddington RS, Robertson EJ: An assessment of the developmental potential of embryonic stem cells in the midgestation mouse embryo. Development 1989, 105:733-737.

12. Niwa H, Toyooka Y, Shimosato D, Strumpf D, Takahashi K, Yagi R, Rossant J: Interaction between Oct3/4 and $\mathrm{Cdx} 2$ determines trophectoderm differentiation. Cell 2005, 1 23:917-929.

13. Tanaka S, Kunath T, Hadjantonakis A-K, Nagy A, Rossant J: Promotion of trophoblast stem cell proliferation by FGF4. Science 1998, 282:2072-2075.

14. Strumpf D, Mao C-A, Yamanaka Y, Ralston A, Chawengsaksophak K, Beck $F$, Rossant J: Cdx2 is required for correct cell fate specification and differentiation of trophectoderm in the mouse blastocyst. Development 2005, 132:2093-2102.

15. Lehnertz B, Ueda Y, Derijck AAHA, Braunschweig U, Perez-Burgos L, Kubicek S, Chen T, Li E, Jenuwein T, Peters AHFM: Suv39h-mediated histone $\mathrm{H} 3$ lysine 9 methylation directs DNA methylation to major satellite repeats at pericentric heterochromatin. Curr Biol 2003, I 3: I 192-1200.

16. Peters AH, O'Carroll D, Scherthan H, Mechtler K, Sauer S, Schofer C, Weipoltshammer K, Pagani M, Lachner M, Kohlmaier A, Opravil S, Doyle M, Sibilia M, Jenuwein T: Loss of the Suv39h histone methyltransferases impairs mammalian heterochromatin and genome stability. Cell 200I, 107:323-337.

17. Loh YH, Wu Q, Chew JL, Vega VB, Zhang W, Chen X, Bourque G, George J, Leong B, Liu J, Wong KY, Sung KW, Lee CW, Zhao XD, Chiu KP, Lipovich L, Kuznetsov VA, Robson P, Stanton LW, Wei CL, Ruan Y, Lim B, Ng HH: The Oct4 and Nanog transcription network regulates pluripotency in mouse embryonic stem cells. Nat Genet 2006, 38:43I-440.

18. Niwa H, Miyazaki J, Smith AG: Quantitative expression of Oct-3/ 4 defines differentiation, dedifferentiation or self-renewal of ES cells. Nat Genet 2000, 24:372-376.

19. Boyer LA, Lee TI, Cole MF, Johnstone SE, Levine SS, Zucker JP, Guenther MG, Kumar RM, Murray HL, Jenner RG, Gifford DK, Melton DA, Jaenisch R, Young RA: Core transcriptional regulatory circuitry in human embryonic stem cells. Cell 2005, 122:947-956.

20. Weis K, Rambaud S, Lavau C, Jansen J, Carvalho T, Carmo-Fonseca M, Lamond A, Dejean A: Retinoic acid regulates aberrant nuclear localization of PML-RAR $\alpha$ in acute promyelocytic leukemia cells. Cell 1994, 76:345-356.

21. Dyck JA, Maul GG, Miller WH, Chen JD, Kakizuka A, Evans RM: A novel macromolecular structure is a target of the promyelocyte-retinoic acid receptor oncoprotein. Cell 1994, 76:333-343.

22. Kamitani T, Kito K, Nguyen HP, Wada H, Fukuda-Kamitani T, Yeh ETH: Identification of three major sentrinization sites in PML. J Biol Chem 1998, 273:26675-26682.

23. Zhong S, Muller S, Ronchetti S, Freemont PS, Dejean A, Pandolfi PP: Role of SUMO-I-modified PML in nuclear body formation. Blood 2000, 95:2748-2752.

24. Muller S, Matunis MJ, Dejean A: Conjugation with the ubiquitinrelated modifier SUMO-I regulates the partitioning of $P M L$ within the nucleus. EMBO J 1998, 17:61-70.

25. Shen TH, Lin H-K, Scaglioni PP, Yung TM, Pandolfi PP: The mechanisms of PML-nuclear body formation. Mol Cell 2006, 24:33I-339.

26. Sampson DA, Wang M, Matunis MJ: The small ubiquitin-like modifier-I (SUMO-I) consensus sequence mediates Ubc9 binding and is essential for SUMO-I modification. J Biol Chem 200I, 276:21664-21669.

27. Hannich JT, Lewis A, Kroetz MB, Li S-J, Heide H, Emili A, Hochstrasser M: Defining the SUMO-modified proteome by multiple approaches in Saccharomyces cerevisiae. I Biol Chem 2005, 280:4102-4II0.

28. Hecker C-M, Rabiller M, Haglund K, Bayer P, Dikic I: Specification of SUMOI- and SUMO2-interacting motifs. J Biol Chem 2006 28I: $|6| 17-16 \mid 27$

29. Minty A, Dumont X, Kaghad M, Caput D: Covalent modification of p73 $\alpha$ by SUMO-I. Two-hybrid screening with p73 identifies novel SUMO-I-interacting proteins and a SUMO-I interacting motif. J Biol Chem 2000, 275:36316-36323.

30. Song J, Durrin LK, Wilkinson TA, Krontiris TG, Chen Y: Identification of a SUMO-binding motif that recognizes SUMO-modified proteins. Proc Natl Acad Sci USA 2004, I0 I: | 4373-14378.
3I. Kim J, Chu J, Shen X, Wang J, Orkin SH: An extended transcriptional network for pluripotency of embryonic stem cells. Cell 2008, 132:1049-1061.

32. Liang J, Wan M, Zhang Y, Gu P, Xin H, Jung SY, Qin J, Wong J, Cooney AJ, Liu D, Songyang Z: Nanog and Oct4 associate with unique transcriptional repression complexes in embryonic stem cells. Nat Cell Biol 2008, 10:731-739.

33. Nacerddine K, Lehembre F, Bhaumik M, Artus J, Cohen-Tannoudji M, Babinet C, Pandolfi PP, Dejean A: The SUMO pathway is essential for nuclear integrity and chromosome segregation in mice. Dev Cell 2005, 9:769-779.

34. Park SW, Hu X, Gupta P, Lin Y-P, Ha SG, Wei L-N: SUMOylation of Tr2 orphan receptor involves $\mathrm{Pml}$ and fine-tunes Oct4 expression in stem cells. Nat Struct Mol Biol 2007, 14:68-75.

35. Lee TI, Johnstone SE, Young RA: Chromatin immunoprecipitation and microarray-based analysis of protein location. Nat Protocols 2006, I:729-748.

36. Nelson JD, Denisenko O, Sova P, Bomsztyk K: Fast chromatin immunoprecipitation assay. Nucl Acids Res 2006, 34:e2.
Publish with Biomed Central and every scientist can read your work free of charge

"BioMed Central will be the most significant development for disseminating the results of biomedical research in our lifetime. "

Sir Paul Nurse, Cancer Research UK

Your research papers will be:

- available free of charge to the entire biomedical community

- peer reviewed and published immediately upon acceptance

- cited in PubMed and archived on PubMed Central

-yours - you keep the copyright 